\title{
Clobazam for Refractory Childhood Seizure Disorders - A Valuable Supplementary Drug
}

\author{
Robert Munn, Peter Camfield, Carol Camfield and Joseph Dooley
}

\begin{abstract}
Clobazam is a new benzodiazepine recently introduced in Canada on an experimental basis. We report our experience with 27 children (average age 9.1 years) with severe intractable seizure disorders. All had mixed seizures (41\% focal plus generalized, $59 \%$ mixed generalized) and $93 \%$ were mentally retarded. Eighty-five percent had multiple daily seizures and all had been on an average of 6 other anticonvulsants in the past. Forty-one percent of our patients responded to clobazam with a reduction of greater than $75 \%$ in seizure frequency and $15 \%$ had no further seizures. Tolerance to clobazam which could not be overcome by dose increases developed in $26 \%$ of patients. Fortyfour percent of non-responders had exacerbations of their seizures shortly after starting clobazam, however $43 \%$ of these patients had reductions in comedications simultaneously. Side effects of clobazam in responders were minimal. We conclude that clobazam shows sufficient promise to warrant further trials in more benign seizure disorders in children.

RÉSUMÉ: Le clobazam dans le traitement des crises convulsives réfractaires chez l'enfant - Un médicament d'appoint précieux Le clobazam est une nouvelle benzodiazépine qui a été introduite au Canada récemment sur une base expérimentale. Nous rapportons notre expérience chex 27 enfants (âge moyen 9.1 ans) présentant des crises convulsives réfractaires au traitement. Tous avaient des crises mixtes (focales et généralisées chex $41 \%$, mixtes généralisées chez $59 \%$ ) et $93 \%$ souffraient d'un retard mental. Quatre-vingt-cinq pourcent présentaient plusieurs crises par jour et tous avaient reçu en moyenne 6 autres anticonvulsivants par le passé. Quarante-et-un pourcent de nos patients ont répondu au clobazam par une réduction de la fréquence des crises de plus de $75 \%$ et $15 \%$ n'ont pas présenté d'autre crise. Vingt-six pourcent des patients ont développé une tolérance au clobazam qui n'a pu être vaincue par une augmentation de la posologie. Quarante-quatre pourcent des non-répondeurs ont présenté une exacerbation des crises peu après avoir commencé à prendre le clobazam. Cependant, la médication associée a été réduite simultanément chez $43 \%$ de ces patients. Les effets secondaires du clobazam ont été minimes chez les répondeurs. Nous concluons que le clobazam est suffisamment prometteur pour justifier des études ultérieures chez les enfants atteints de désordres convulsifs plus bénins.
\end{abstract}

Can. J. Neurol. Sci. 1988; 15: 406-408

The 1,4 benzodiazepines, especially nitrazepam and clonazepam, are well recognized in the treatment of a variety of seizure disorders in childhood. ${ }^{1}$ Their use however has been largely limited to seizure types resistent to conventional antiepileptic treatment such as myoclonic, atonic, atypical absence seizures, status epilepticus and infantile spasms. Major disadvantages of the 1,4 benzodiazepines include their sedative and muscle relaxant properties and possible deleterious effect on higher cognitive functions.

A 1,5 benzodiazepine (Clobazam) has been introduced in Canada on an experimental basis. Its chemical structure differs from other benzodiazepines by the position of the nitrogen atoms on the diazepine ring. Clobazam is well absorbed from the gastrointestinal tract and peak plasma concentrations are reached within 1-3 hours. ${ }^{2}$ Of identified metabolites, $\mathrm{N}$ desmethylclobazam appears to be the most important and has $1 / 4-1 / 5$ the potency of clobazam.2.3.4 The half-life of clobazam is 18 hours compared to $33-133$ hours for $\mathrm{N}$-desmethylclobazam. ${ }^{\mathrm{s}}$
Clobazam was originally introduced in 1975 in France because of its anxiolytic properties but was subsequently found to have antiepileptic effects. ${ }^{6,7}$ Several open studies suggest that clobazam has less sedative and muscle relaxant properties than the 1,4 benzodiazepines and may perhaps "brighten" some cognitive functions. ${ }^{1.5,7,8,9} \mathrm{~A}$ disadvantage of clobazam like the 1,4 benzodiazepines is the development of tolerance which occurs in $12-56 \%$ of patients. ${ }^{10,11,12,14}$

Only one North American center has reported its experience with clobazam in children. ${ }^{1}$ The purpose of this study was to review all patients in whom clobazam had been used at the Izaak Walton Killam Hospital for Children in Halifax.

\section{Methods ANd Results}

Patients were begun on clobazam between Dec. 1985 and Nov. 1986 with followup in Jan. 1987 and May 1987. All patients were started on a BID schedule of clobazam because of intractable seizures. Twenty-seven children (17 males, 10

From the Department of Paediatrics, Izaak Walton Killam Hospital for Children, Dalhousie University, Halifax

Presented in part at the Canadian Congress of Neurological Science meeting, June 1987, Vancouver, British Columbia

Received March 17, 1988. Accepted May 17, 1988

Reprint requests to: Dr. P. Camfield, I.W.K. Hospital for Children, 5850 University Ave., Halifax, Nova Scotia, Canada B3J 3G9 
Table 1. Responders Versus Non-responders to Clobazam

\begin{tabular}{|c|c|c|}
\hline & RESPONDERS & NON-RESPONDERS \\
\hline n & 11 & 16 \\
\hline $\begin{array}{l}\text { Average Dose of } \\
\text { Clobazam }\end{array}$ & $\begin{array}{l}1.3 \mathrm{mg} / \mathrm{kg} / \mathrm{day} \\
\text { (range } 0.3-2.9 \text { ) }\end{array}$ & $\begin{array}{l}.72 \mathrm{mg} / \mathrm{kg} / \mathrm{day} \\
\text { (range } 0.1-1.5 \text { ) }\end{array}$ \\
\hline Seizure Control & $\begin{array}{l}>75 \% \text { reduction } \\
\text { in seizure frequency }\end{array}$ & no improvement \\
\hline Side Effects & $\begin{array}{l}\text { Hyperactivity (1) } \\
\text { drooling (1) } \\
\text { transient vomiting (1) } \\
\text { anorexia (1) }\end{array}$ & $\begin{array}{l}\text { sedation (5) } \\
\text { ataxia (2) } \\
\text { irritability (2) }\end{array}$ \\
\hline
\end{tabular}

females) with an average age of 9.1 years (2.4-20.1 years) were identified. Twenty-five $(93 \%)$ of the children were mentally retarded (16 mild-moderate mental retardation, 9 severe) and the remaining 2 had learning disabilities. Seven children (26\%) had major neurological physical findings. Possible cause for the seizures was identified in 10 children $(37 \%)$ but none of these patients had progressive neurological disease.

Eleven children had focal plus generalized seizures and 16 had mixed generalized seizure disorders. Twenty-three children (85\%) had multiple daily seizures. Twenty-one patients $(78 \%)$ had received a course of ACTH and all patients had previously received an average of $6(2-8)$ other anticonvulsants, both indicating refractory epilepsy. At the time of starting clobazam the children were taking an average of 3 (1-7) other anticonvulsants.

Eleven patients $(41 \%)$ had a favorable response to clobazam all having a greater than $75 \%$ reduction in seizure frequency (Table 1). Average length of treatment for the responders at the time of the May 1987 evaluation was 44 weeks (24-78). Four patients $(15 \%)$ had no further seizures. Six of the 11 responders had reductions in comedications. One responder had an additional anticonvulsant prescribed during clobazam treatment (Ethosuximide). Five patients required dose increases to maintain clinical efficacy. Doses ranged from $0.30 \mathrm{mg} / \mathrm{kg} / \mathrm{day}$ $2.9 \mathrm{mg} / \mathrm{kg} /$ day in responders. The average starting dose was $0.5 \mathrm{mg} / \mathrm{kg} /$ day with an average final dose of $1.3 \mathrm{mg} / \mathrm{kg} /$ day. All parents of responders reported improved alertness.

Sixteen patients $(59 \%)$ were identified as being non-responders to clobazam (Table 1). Fourteen of these children stopped the drug after an average of 16.4 weeks (2-38 weeks) of treatment. One patient remained on clobazam with no change in seizure status. Another child died in status epilepticus 10 days after clobazam was started and as nitrazepam was being weaned. At the time of his death nitrazepam had been weaned over a 10 day period from $1.5 \mathrm{mg} / \mathrm{kg} /$ day to $0.38 \mathrm{mg} / \mathrm{kg} /$ day. $\mathrm{He}$ was a six-year-old boy with mild mental retardation and multiple daily myoclonic and generalized tonic-clonic seizures. His sister, who was not on clobazam but also had a similar seizure disorder, died in her sleep one year later at the age of five presumably of an unwitnessed seizure at a time when anticonvulsants were not being changed. Thus it is not entirely clear whether the episode of status epilepticus was precipitated by the reduction of nitrazepam or the addition of clobazam.
Fourteen patients discontinued clobazam because of side effects, lack of clinical efficacy or exacerbation of seizures. Seven patients $(26 \%)$ had exacerbations of their seizures although 3 had reductions in comedications simultaneously ( 1 carbamazepine, 1-nitrazepam, 1-valproate).

Five of the patients who discontinued clobazam had dose increases with no change in seizure status. Four required dose decreases because of side effects with no improvement. Average final dose prior to discontinuing clobazam was $0.72 \mathrm{mg} / \mathrm{kg} /$ day $(0.1-1.5 \mathrm{mg} / \mathrm{kg} /$ day) in the non-responders.

Seven of the non-responders $(26 \%)$ developed tolerance to clobazam which could not be recaptured. This included 4 patients who initially had a positive response when evaluated at an average of 15.5 weeks of treatment (6-20 weeks). Three of these patients initially showed a $50-75 \%$ reduction in seizure frequency and one had a greater than $75 \%$ reduction. When reevaluated at an average of 33.5 weeks ( 24 - 38 weeks) of treatment the drug was being stopped because of the development of lack of efficacy. Another 3 patients had an early reduction in seizure frequency but this response disappeared within 2 - 4 weeks.

Side effects of clobazam were sedation, ataxia, irritability and anorexia in non-responders. In responders hyperactivity, increased drooling and transient vomiting with dose increases were all noted once.

Clinical toxicity was noted once with phenytoin and once with nitrazepam. One child just after starting clobazam became ataxic and was found to have a toxic phenytoin level of $110 \mathrm{mmol} /$ liter. He had had no change in his phenytoin dose and was in the therapeutic range prior to starting clobazam. His phenytoin dose was lowered and the ataxia disappeared. Another on nitrazepam became emotionally labile when clobazam was added which resolved when clobazam was discontinued.

As far as could be determined there was no difference in the neurological status, seizure type or comedications in responders versus non-responders.

\section{Discussion}

A number of paediatric studies have reviewed the results of clobazam in children (Table 2). Cano et $\mathrm{al}^{3}$ in a study designed to investigate the effect of anti-epileptic drugs on the pharmacokinetics and metabolism of clobazam were able to look at the clinical efficacy of clobazam in 59 of 86 patients (average age 16 , range 3 - 35). Fifty percent had a greater than $50 \%$ reduction in seizure frequency and $29 \%$ remained seizure free at three months. Shimizu et al ${ }^{13}$, with 36 children (average age 8 , range 1 - 16) who had mixed intractable seizure disorders found $50 \%$ of patients had a greater than $50 \%$ reduction in seizure frequency and $25 \%$ were seizure free at one year.

Twenty-two percent of the children developed some tolerance to clobazam with an initial reduction and subsequent increase in seizure frequency. In the responders an antiepileptic effect occurred within the first 10 days after starting clobazam. Dulac et al ${ }^{14}$ used clobazam as monotherapy in 25 epileptic children (average age 6, range 6 mos. - 16 years) for periods up to three years. Sixty-four percent had a greater than $75 \%$ reduction in seizure frequency and $44 \%$ remained seizure free. Seizures recurred in $12 \%$ of patients within a few weeks of 


\begin{tabular}{|c|c|c|c|c|c|}
\hline $\begin{array}{l}\text { Study } \\
\text { (Year) }\end{array}$ & $\begin{array}{l}\text { No. } \\
\text { Pts. }\end{array}$ & $\begin{array}{c}\%>50 \% \\
\text { Improvement }\end{array}$ & $\begin{array}{c}\text { \% Seizure } \\
\text { Free }\end{array}$ & $\begin{array}{l}\text { Study Length } \\
\text { (Months) }\end{array}$ & $\begin{array}{c}\text { Tolerance } \\
(\%)\end{array}$ \\
\hline $\begin{array}{l}\text { Cano } \\
(81)\end{array}$ & 59 & 50 & 29 & 3 & - \\
\hline $\begin{array}{l}\text { Shimizu } \\
\text { (82) }\end{array}$ & 36 & 50 & 25 & 12 & 22 \\
\hline $\begin{array}{l}\text { Dulac } \\
(83)\end{array}$ & 25 & 64 & 44 & 36 & 12 \\
\hline $\begin{array}{l}\text { Farrell } \\
(86)\end{array}$ & 50 & 54 & 20 & $\begin{array}{c}3 \\
\text { Minimum }\end{array}$ & 34 \\
\hline $\begin{array}{l}\text { Munn } \\
(87)\end{array}$ & 27 & 41 & 15 & 10 & 26 \\
\hline
\end{tabular}

starting clobazam, after initially showing an improvement. Farrell' described 50 children with refractory seizure disorders in whom clobazam was used as adjunctive therapy. With a minimum of 3 months of followup, $54 \%$ had a greater than $50 \%$ reduction in seizure frequency and $20 \%$ became seizure free. He noted increased alertness in $68 \%$ of his patients while on clobazam. Tolerance occurred in 34 percent.

Forty-one percent of our patients responded to clobazam with a reduction of greater than $75 \%$ in seizure frequency. Fifteen percent had no further seizures. Tolerance to clobazam in our study which could not be overcome by dose increases developed in $26 \%$ of patients either early ( $2-4$ weeks) or later ( 24 - 38 weeks). As well, 5 of the 11 responders $(45 \%)$ required dose increases to maintain clinical efficacy in the first few weeks of treatment.

Of concern is the exacerbation of seizures noted in $26 \%$ of our patients. Forty-three percent of patients with exacerbations however had reductions in comedications simultaneously. One patient died while being weaned from nitrazepam which may indicate other benzodiazepines should be slowly tapered.

Based on our experience, a gradual introduction of clobazam seems prudent as some patients had exacerbations of their seizures shortly after starting clobazam. If a clinical response is evident other anticonvulsants should be withdrawn one at a time and slowly. The effective dose appears to be approximately $1.3 \mathrm{mg} / \mathrm{kg} /$ day $(0.3$ to $2.9 \mathrm{mg} / \mathrm{kg} /$ day $)$ in children.

Clobazam shows sufficient promise to warrant further trials in both complex and more benign seizure disorders in children. It appears useful as an add-on drug, and is reasonably well tolerated without producing sedation. Interactions with other anticonvulsants are not a major problem. Double-blind placebo crossover studies are needed to compare the 1,4 benzodiazepines to the 1,5 benzodiazepines in combination with other drugs and as monotherapy. 